\title{
Strategic framework for New Zealand grapevine trunk disease
}

\author{
D.C. Mundy
}

The New Zealand Institute for Plant \& Food Research (PFR) Limited, Marlborough Wine Research Centre (MWRC), P.O. Box 845, Blenheim, New Zealand

Grapevine trunk diseases (GTDs) threaten the longevity of vineyards in New Zealand and internationally. Researchers and wine industry representatives met in Christchurch in November 2016 to develop a strategic plan to enhance the progress of GTD research and improve consistency across studies in New Zealand over the next ten years. Four outcome areas were identified: disease prevention and improved sustainability; improved management decisions; fewer susceptible vines; and improved pathogen management in nurseries and young vines. The group used these outcomes to determine four research focus areas: Disease Etiology/Pathology; Biologicals affecting the host or pathogen; Breeding; and Physiology (including a holistic measure of plant health and biochemistry). The focus areas and outcomes were used to develop a framework that takes into account current research or related activities, any challenges or issues involved, future research required (underpinning and applied), and potential for technology transfer. Attendees also summarised recent research activity and identified current knowledge gaps. Researchers agreed to: enhance sharing of methods and isolates; improve comparisons between experimental results; and increase awareness of the current range of activities and skills employed. Publishing the framework on the MWRC and PFR websites will allow other researchers to access, and comment on, current thinking on this topic.

\section{Suppression of Neonectria ditissima growth on agar by Bacillus- based products}

\author{
B.M. Fisher ${ }^{1}$, G. Gubellini' ${ }^{2}$ P.N. Wood ${ }^{1}$ and R.W.A. Scheper ${ }^{1}$ \\ ${ }^{1}$ The New Zealand Institute for Plant \& Food Research Limited, Private Bag 1401, Havelock North 4130, \\ New Zealand \\ ${ }^{2}$ Scuola di Agraria e Medicina Veterinaria- Università di Bologna, Bologna, Italy \\ Corresponding author: brent.fisher@plantandfood.co.nz
}

European canker (Neonectria ditissima), is an important disease on apple trees. Four biological Bacillusbased products and four fungicidal products were tested for efficacy against this pathogen on water agar (WA) and potato dextrose agar (PDA). Neonectria ditissima colonies grown without the biological products were healthy, but when mixed with biological control agents, the colonies were smaller and more diffuse. An interaction between medium and product was observed at $20^{\circ} \mathrm{C}$. Bacstar ${ }^{\mathrm{TM}}$, Serenade ${ }^{\circledR}$ Optimum and TripleX ${ }^{\mathrm{TM}}$ reduced colony growth on PDA but not on WA, while Fulzyme ${ }^{\circledR}$ Plus reduced colony growth on WA but less on PDA. Interestingly, the efficacy of the products was not improved when 10 times label rates were used, except for Fulzyme Plus on WA. At $10^{\circ} \mathrm{C}$ and $15^{\circ} \mathrm{C}$ Fulzyme Plus was the most effective biological product, particularly at 10 times label rate. Activation of the biological products $\left(25^{\circ} \mathrm{C}\right.$ for $3 \mathrm{~h}$ ) did not increase their efficacy. Capetec ${ }^{\mathrm{TM}}$ (captan) and a mixture of HML32 $2^{\mathrm{TM}}$ + HML Silco $^{\mathrm{TM}}$ prevented pathogen growth. ARMOUR-Zen ${ }^{\circledR}$ and Esteem ${ }^{\circledR}$ did not reduce the number of colonies. More research is needed to determine whether biological products can be used to control European canker. 